\title{
Efeito da setorização no controle das pressões na rede de distribuição de água pela inserção de válvulas redutoras de pressão
}

Effect of sectoralization in the control of the pressures in the water distribution network, through the insertion of reducing pressure valves

\author{
Data de entrada: \\ 03/10/2018 \\ - Data de aprovação: \\ 08/04/2019
}

DOI: https://doi.org/10.36659/dae.2020.066

Daniela Moraes da Costa ${ }^{1 *}$ | Jhully Laiane Souza da Silva ${ }^{1}$ | Gilberto Caldeira Barreto ${ }^{2}$ | Monique Sandra Oliveira Dias Barreto ${ }^{2}$

Barreto GC (D) https://orcid.org/0000-0001-6471-8298

Barreto MSOD (D) https://orcid.org/0000-0002-7667-7451
ORCID ID

Costa DM (D) https://orcid.org/0000-0001-8222-6377

Silva JLS (D) https://orcid.org/0000-0003-1316-1607

\section{Resumo}

O presente trabalho tem por objetivo apresentar o efeito da setorização no controle das pressões na rede de distribuição de água pela inserção de válvulas redutoras de pressão (VRP). 0 estudo de caso foi a rede de distribuição de água da Vila Residencial de Tucuruí -PA, para a qual foram propostas três concepções de setorização. Para isso, utilizou-se o software de simulação hidráulica EPANET 2.0 a fim de decidir a melhor concepção de setorização. As concepções foram denominadas cenários 1, 2 e 3. Esses cenários foram definidos (desenhados) considerando o conceito de Distrito de Medição e Controle (DMC), tamanho do setor e pressões requeridas, como recomenda a NBR 12218/2017. Além disso, foram avaliados os custos de substituição ou instalação de válvulas para a criação dos DMCs. Após as simulações dos cenários, observou-se que o cenário 3 apresentou o melhor desempenho hidráulico, atendendo em $99 \%$ as pressões requeridas na rede.

Palavras-chave: Setorização. Rede de distribuição de água. EPANET 2.0. DMC. Pressão. Válvulas.

\section{Abstract}

The present study aims to present the effect of the sectorization in the control of the pressures in the water distribution network, through the insertion of pressure reducing valves (VRP). The case study was applied to the water distribution network of Vila Residencial of Tucurui - PA, which proposed three conceptions of sectorization. For this purpose, the EPANET 2.0 hydraulic simulation software was used to decide the best sector design. The conceptions were called scenarios: 1, 2 and 3. These scenarios were defined (drawn) considering the concept of Measurement and Control District (DMC), sector size and required pressures, as recommended by NBR 12218/2017. In addition, the costs of replacing or installing valves to create the DMCs were evaluated. After simulations of the scenarios, it was observed that scenario 3 presented the best hydraulic performance, attending $99 \%$ of the required pressures in the network.

Keywords: Sectorization. Water distribution network. EPANET 2.0. DMC. Pressure. Valves.

\footnotetext{
${ }^{1}$ Instituto Federal de Educação, Ciência e Tecnologia do Estado do Pará (IFPA) - Tucuruí - Pará - Brasil.

2 Universidade Federal do Pará (UFPA) - Belém - Pará - Brasil.

*Autora correspondente: danielamooraesagmail.com.
} 


\section{INTRODUÇÃO}

Visando beneficiar o planejamento e o controle da operação, é de fundamental importância o controle da pressão na rede, para a redução de perdas reais (físicas) em sistemas urbanos de distribuição de água tratada (BEZERRA et al., 2010).

Para Gomes (2011), uma alternativa para o equilíbrio das pressões do sistema de distribuição é a setorização de redes, que consiste basicamente na divisão de uma rede em setores isolados. Dessa maneira, permite o razoável controle de pressões e o aperfeiçoamento da operação e manutenção das redes por meio do fechamento de válvulas de manobra.

De acordo com Oliveira (2013), a instalação de Válvulas Redutoras de Pressão (VRP) pressupõe a delineação de um subsetor perfeitamente isolado, configurando um Distrito de Medição e Controle (DMC). Segundo Motta (2010), um Sistema de Abastecimento de Água (SAA) seria totalmente eficiente se sua rede de distribuição atendesse ao nível de pressão mínimo aceitável, sem nunca comprometer o pleno fornecimento de água.

Portanto, a utilização de ferramentas computacionais nas diversas áreas de engenharia vem se tornando cada vez mais frequente e necessária para a setorização de redes de distribuição de água, pois há economia de tempo e possibilidade de realizar análises mais detalhadas da rede (DIUANA E OGAWA, 2015).

Há diversos simuladores hidráulicos disponíveis para a modelagem e simulação de sistemas de distribuição de água. Dentre os programas de simulação hidráulica, destaca-se o EPANET 2.0, pois, segundo Rossman et. al (2000), trata-se de um programa de fácil utilização, com versões nos principais idiomas.

Como a setorização é uma medida estratégica que vem apresentando grande eficácia no controle das pressões na rede de distribuição de água, este trabalho tem como objetivo apresentar o efeito da setorização no controle das pressões na rede de distribuição água por meio da inserção de VRP. Considerou-se como área de estudo a rede de distribuição de água da Vila Residencial de Tucuruí - PA, para a qual foram propostas três concepções de setorização. Para isso utilizou-se o simulador hidráulico EPANET 2.0 a fim de analisar o comportamento das pressões do setor após dividi-lo em DMC e inserir VRPs.

\section{METODOLOGIA}

Considerou-se como área de estudo a rede de distribuição de água da Vila Residencial, localizada no município de Tucuruí - Pará (Fig. 1).

A rede de distribuição em estudo ocupa uma área entorno de $5.29 \mathrm{~km}^{2}$, responsável pelo fornecimento de água tratada de 2.564 residências (Setor de Saneamento da Vila Residencial, 2018). A população da Vila é de aproximadamente de 10.540 habitantes $^{1}$, o que resulta em uma ocupação média de quatro (04) habitantes por domicílio ${ }^{2}$, com consumo per capita de água de 835,65 L/hab. dia .

Os diâmetros da rede variam de $65 \mathrm{~mm}$ a 450 $\mathrm{mm}$, com predominância do diâmetro de $75 \mathrm{~mm}$, como mostra a Tabela 1.

\footnotetext{
${ }^{1}$ População estimada com base no dado censitário de 2010 e estimativa populacional 2017, do Instituto Brasileiro de Geografia e Estatística (IBGE).

${ }^{2}$ Ocupação média calculada com base na população e número de residências (população dividida pelo número de residência).

${ }^{3}$ Per capita calculada considerando o volume mensal distribuído (Setor de Saneamento da Vila Residencial da Eletronorte, 2018) e a população total, utilizando a seguinte equação: q=(vol.dist.mês (L))/(dias do mes x pop.). Onde: q = per capita (L/hab.dia);
} 
Figura 1: Mapa de localização da área de estudo.

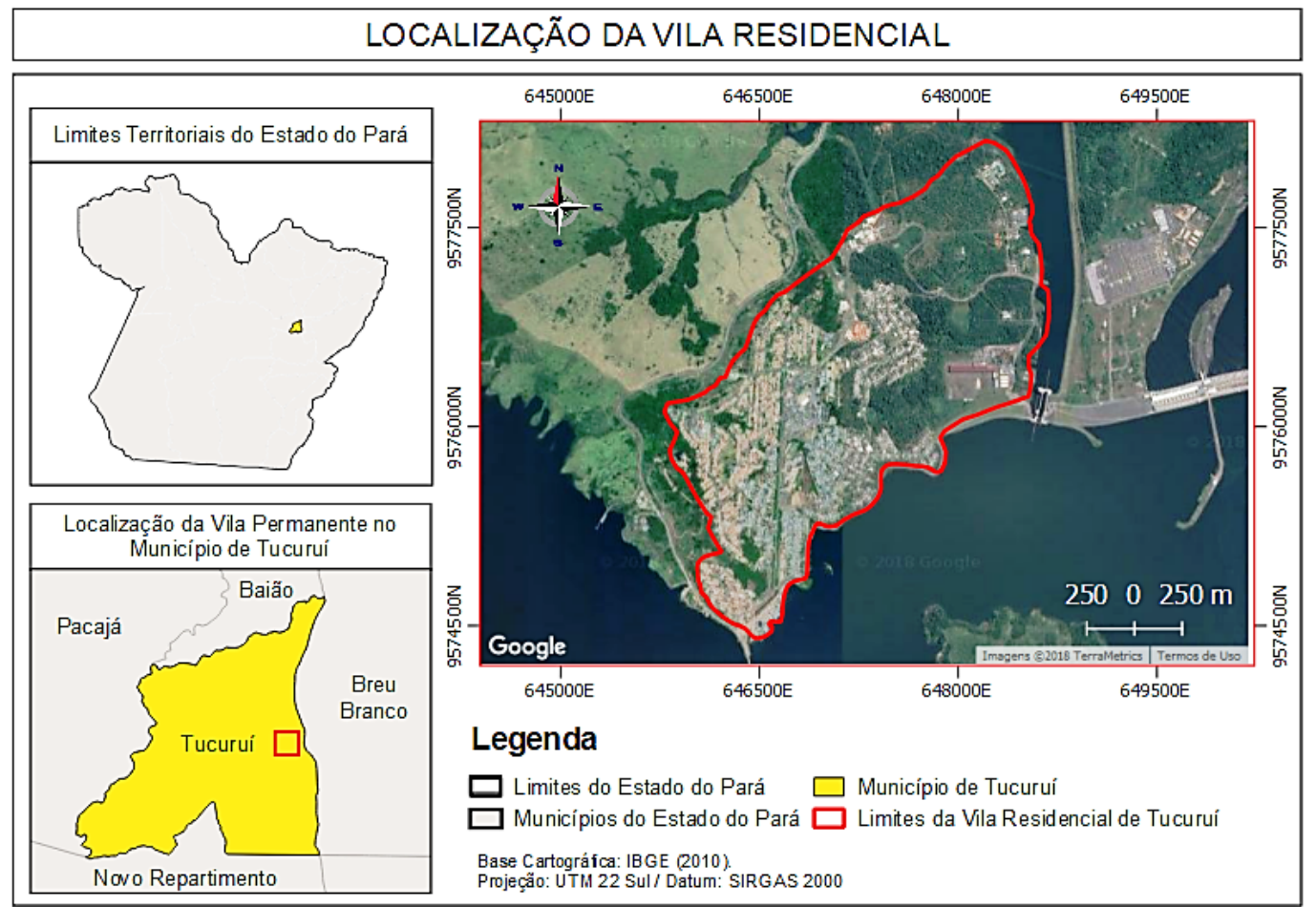

Fonte: Autoras, 2018.

Tabela 1: Diâmetros e extensão da rede de distribuição da Vila Residencial.

\begin{tabular}{|c|c|}
\hline \multicolumn{2}{|c|}{ Rede de Distribuição } \\
\hline $\begin{array}{c}\text { Diâmetro } \\
(\mathbf{m m})\end{array}$ & $\begin{array}{c}\text { Extensão } \\
(\mathbf{m})\end{array}$ \\
\hline 65 & 159,17 \\
\hline 75 & $12.574,13$ \\
\hline 100 & $6.796,36$ \\
\hline 112 & $1.175,80$ \\
\hline 150 & $11.059,03$ \\
\hline 200 & $2.063,50$ \\
\hline 250 & $2.797,34$ \\
\hline 300 & 561,09 \\
\hline 400 & $1.337,37$ \\
\hline 450 & 995,26 \\
\hline Extensão Total & $39.519,05$ \\
\hline
\end{tabular}

Fonte: Autoras, 2018.
A rede de distribuição de água da Vila Residencial foi escolhida por não ser setorizada e ter mais de 40 anos de operação, o que aponta para dados confiáveis em relação às pressões internas da rede. Tais pressões são extremamente elevadas e não estão dentro dos valores estabelecidos pela NBR 12218/2017, que trata do Projeto de Rede de Distribuição de Água para Abastecimento Público. Vale salientar que o município de Tucuruí não realiza cobrança pelo fornecimento de água.

A metodologia utilizada neste trabalho dividiu-se em quatro etapas, conforme apresentado na Fig. 2. 
Figura 2: Etapas do trabalho.

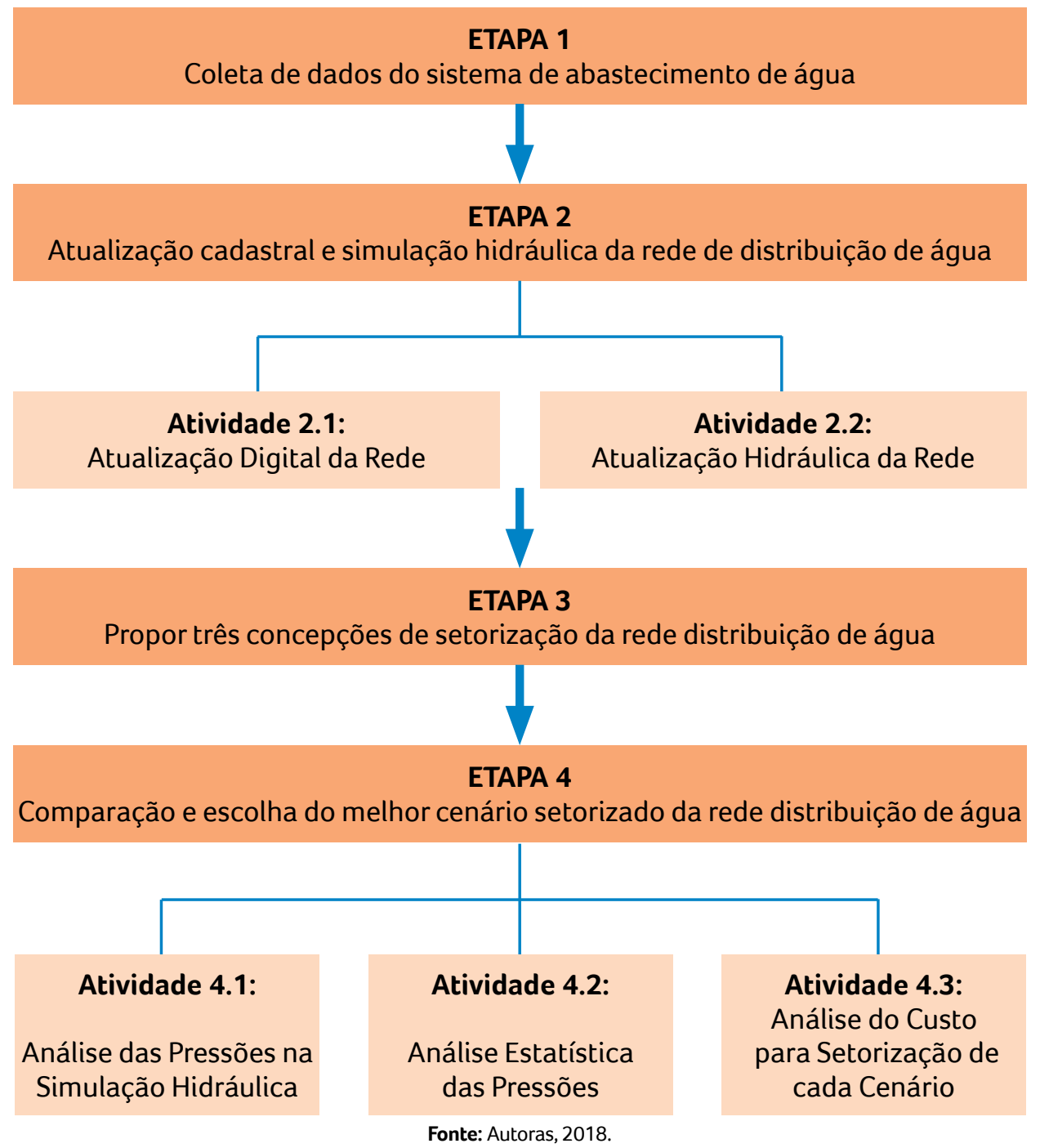

\section{Etapa 1: Coleta de Dados do Sistema de Abastecimento de Água}

Nesta etapa foi realizado o levantamento de informações fidedignas das características físicas e de funcionamento do SAA em estudo. Os dados coletados foram do tipo primário e secundário, obtidos por meio de solicitação formal junto à entidade gestora do setor de saneamento. Para isso, foram feitas visitas in loco em todas as unidades que compõem o SAA, junto com o representante técnico da entidade gestora.
Etapa 2: Atualização Cadastral e Simulação Hidráulica da Rede de Distribuição de Água

$\mathrm{O}$ arquivo digital da rede de distribuição foi atualizado utilizando os dados obtidos na etapa anterior, dados estes inseridos nos softwares AutoCAD, em seguida, no EPANET 2.0.

\section{Atividade 2.1: Atualização Digital da Rede}

No que diz respeito à atualização digital da rede, no programa AutoCAD foram inseridos os trechos da 
rede de distribuição existentes que não constavam no arquivo DWG, bem como seus respectivos diâmetros, introduzindo também, as válvulas existentes na rede que não estavam também no arquivo, em suas respectivas localizações, assim como foram excluídas as redes não mais existentes.

\section{Atividade 2.2: Atualização Hidráulica da Rede}

A atualização e a simulação hidráulica da rede foram feitas no software EPANET 2.0, onde foram inseridos os dados fornecidos pela entidade gestora. Foram inseridos também os componentes físicos e não-físicos, componentes estes de extrema importância, pois só é possível a simulação hidráulica no software se tais componentes forem inseridos. Após configurar os componentes deu-se início à criação da curva de volume, histograma de vazão e padrão temporal.

\section{Etapa 3: Propor Três Concepções de Setorização} da Rede Distribuição de Água

Nesta etapa, foram desenhadas três possíveis concepções de cenários de setorização da rede de distribuição, a fim de adequar as pressões internas da rede, de acordo com o estabelecido na NBR $12.218 / 2017$. Os critérios utilizados para a setorização da rede foram: critério hidráulico (pressão), operacional (mais simples/menos válvulas) e econômico (menos oneroso). Essa etapa foi relacionada à aplicabilidade otimizada das VRP na rede, visando avaliar em qual situação a inclusão ou substituição de válvula de gaveta (VG) por VRP torna o dimensionamento mais adequado, proporcionando benefícios hidráulicos e econômicos para a setorização da rede de distribuição.

Etapa 4: Comparação e Escolha do Melhor Cenário Setorizado da Rede de Distribuição de Água

Nesta etapa foi escolhida a melhor concepção de setorização da rede de distribuição de água da
Vila Residencial por meio de análise hidráulica e econômica de cada cenário.

\section{Atividade 4.1: Análise das Pressões na Simulação Hidráulica}

Para a análise das pressões na rede dos cenários, foram gerados no EPANET 2.0, gráficos de isolinhas de cada cenário, a fim de obter uma melhor visualização das zonas de pressões acima de 50 mca.

\section{Atividade 4.2: Análise Estatística das Pressões}

Foram feitos histogramas horário de pressão, referentes à simulação das 24 horas do dia no $\mathrm{Mi}$ crosoft Excel, cujo objetivo foi comparar o comportamento das pressões dos cenários.

\section{Atividade 4.3: Análise de Custo para a Setorização de cada Cenário.}

Para determinação do custo da setorização de cada concepção, fez-se um orçamento de custo com aquisição das válvulas de cada cenário.

\section{RESULTADOS E DISCUSSÃO}

Os resultados obtidos neste trabalho serão apresentados e discutidos conforme a sequência de execução da metodologia descrita.

\section{Etapa 1: Coleta de Dados do Sistema de} Abastecimento de Água

Para a execução deste trabalho foi necessário, em primeiro lugar, recolher diferentes tipos de dados do sistema de abastecimento de água da Vila Residencial, junto à entidade gestora (Setor Administrativo da Vila Residencial). Para isso foram feitas visitas in loco em cada unidade do SAA, junto com um responsável técnico. O foco principal dessas visitas foi obter o máximo possível de informações sobre o sistema operacio- 
nal da rede em estudo. É importante frisar que não foi possível ter acesso aos dados referentes ao índice de perdas reais, pois a Eletronorte/Eletrobrás não possui medidor de vazão na saída da ETA e devido à não cobrança pelo abastecimento de água, também não existem hidrômetros nos ramais prediais. Portanto, carecendo da falta de informação de tais dados, o mesmo não será abordado no decorrer deste estudo.

A água utilizada no sistema de abastecimento da Vila Residencial é de origem superficial, captada do reservatório do Lago da Usina Hidrelétrica da Eletrobrás - UHE e do Sítio Deus é Grande. Cada captação é feita por conjunto motor bomba (CMB). Vale ressaltar que ambas as captações funcionam de forma alternada, sendo que a captação do Sítio Deus é Grande só opera quando a captação do lago UHE está em manutenção.
A adutora de água bruta do lago UHE é de diâmetro de $450 \mathrm{~mm}$, e o diâmetro da adutora do Sítio Deus é Grande de 300 mm. Estas conduzem a água até a ETA que está localizada na parte alta da Vila. Após o tratamento, a água é armazenada em quatro (4) reservatórios, responsáveis por abastecer toda a Vila Residencial, distribuição feita por gravidade. Três dos reservatórios estão localizados na ETA, sendo dois (2) semi-aterrados, um do lado do outro com capacidade de reservação de $1593 \mathrm{~m}^{3}$ cada, e um (1) elevado que reserva $40 \mathrm{~m}^{3}$ de água; o quarto (4) reservatório possui capacidade de reservar $2000 \mathrm{~m}^{3}$ de água e é abastecido pelos dois reservatórios semiaterrados que estão na ETA.

A "representação" do SAA da Vila Residencial está ilustrada na Fig. 3.

Figura 3: Exemplificação do SAA da Vila Residencial.

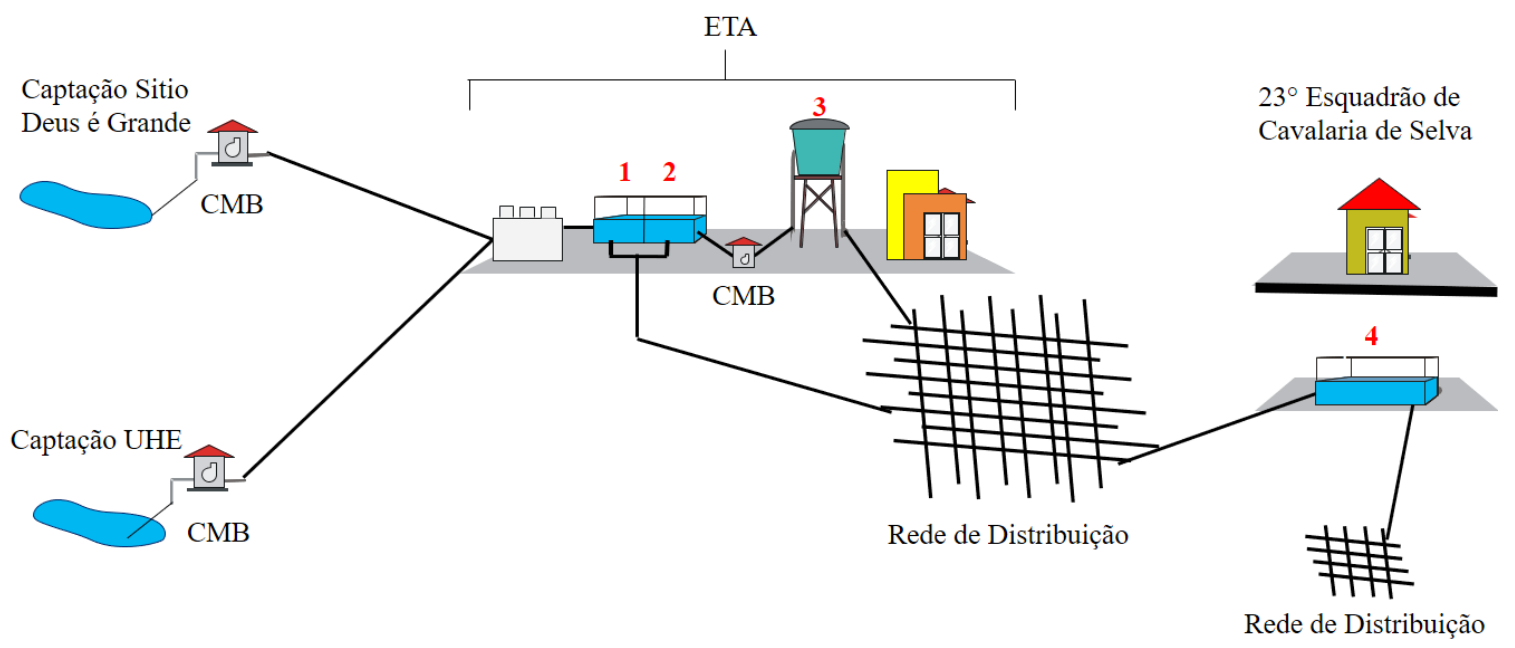

Fonte: Adaptado de Pereira e Condurú, 2010.

Existem instalações em diferentes locais da rede 57 VG, sendo estas utilizadas apenas para manobra de manutenção. É importante destacar que a maioria (cerca de 70\%) das tubulações da rede é de material amianto, e os outros
30\% são constituídos em PVC, e que a área da Vila Residencial possui declividade acentuada, com grande variação de cota topográfica de uma área para outra, sendo a variação de 53 a $196,5 \mathrm{~m}$. 
Etapa 2: Atualização Cadastral e Simulação da Rede de Distribuição de Água da Vila Residencial Nesta etapa foi atualizada a rede por meio dos dados obtidos na etapa anterior com o auxílio do programa AutoCAD e EPANET 2.0, conforme mostra a Fig. 4.

Figura 4: Rede de distribuição de água da Vila Residencial atualizada.

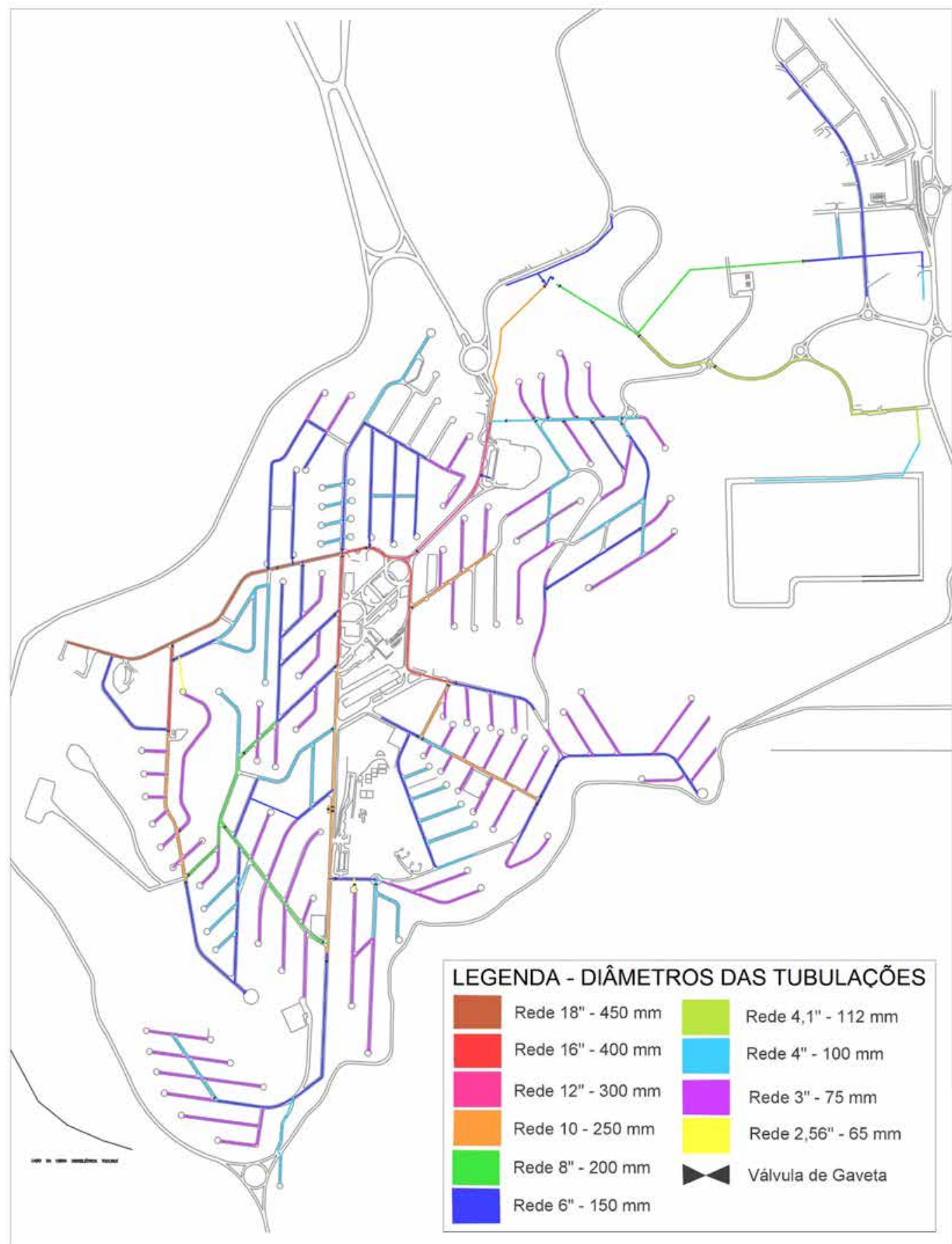

Fonte: Autoras, 2019. 


\section{Atividade 2.1: Atualização Digital da Rede}

Foram inseridos os traçados da rede, bem como seus respectivos diâmetros, cotas topográficas e localização das VG, disponibilizados pela entidade gestora da Vila Residencial, onde foi possível extrair as informações referentes à extensão total da rede, que é de aproximadamente de 39. 519 metros.

\section{Atividade 2.2: Atualização Hidráulica da Rede}

Para a atualização Hidráulica da rede, inseriram-se os componentes físicos e não físicos no software EPANET 2.0, associado a estes um conjunto de propriedades, a que foram atribuídos valores predefinidos. Para a configuração dos componentes físicos, foram adicionados os dados coletados na etapa 1, dados estes expostos na Tabela 2.

Tabela 2: Características Operacionais do Sistema de Distribuição de Água.

\begin{tabular}{|c|c|c|}
\hline Reservatório de nível fixo (RNF) & Nível de água $(\mathrm{m})$ & - \\
\hline Bomba (CMB) & Potência $(\mathrm{CV})$ & 500 \\
\hline \multirow{2}{*}{$\begin{array}{c}\text { Reservatório de nível variado } \\
\text { (RNF) }\end{array}$} & Cota $(\mathrm{m})$ & 196,5 \\
\cline { 2 - 3 } & Altura da água inicial $(\mathrm{m})$ & 4 \\
\cline { 2 - 3 } & Altura da água mínima $(\mathrm{m})$ & 0,3 \\
\hline & Altura de água máxima $(\mathrm{m})$ & 3,7 \\
\hline
\end{tabular}

Fonte: Adaptado de Setor de Saneamento da Vila Residencial, 2018.

Após a inserção dos dados e dispositivos padrões, inseriu-se também no software as válvulas existentes na rede, totalizando 57 VG, em seus respectivos nós e diâmetros.
Para a criação da Curva do Volume foram inseridos dados de altura da água e Volume, utilizando uma planilha de vazão de distribuição fornecida pela entidade gestora (Fig. 5).

Figura 5: Curva do volume.

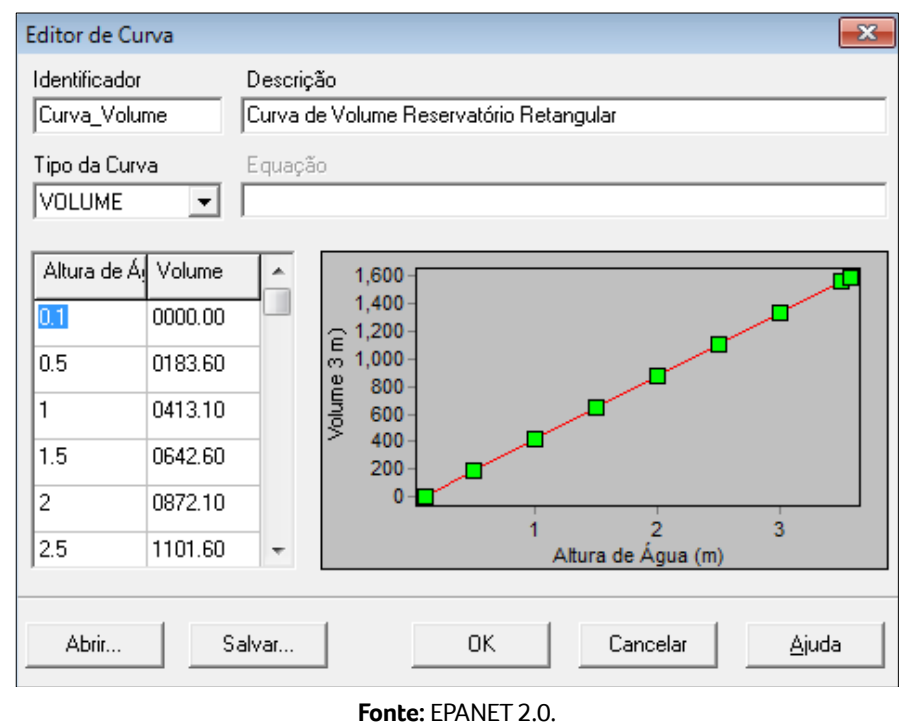

Já para criação do hidrograma de vazão foram inseridos os fatores multiplicativos referentes à vazão de distribuição horária ao longo das 24 horas do dia, como mostra a Fig. 6. 
Figura 6: Hidrograma horário de vazão.

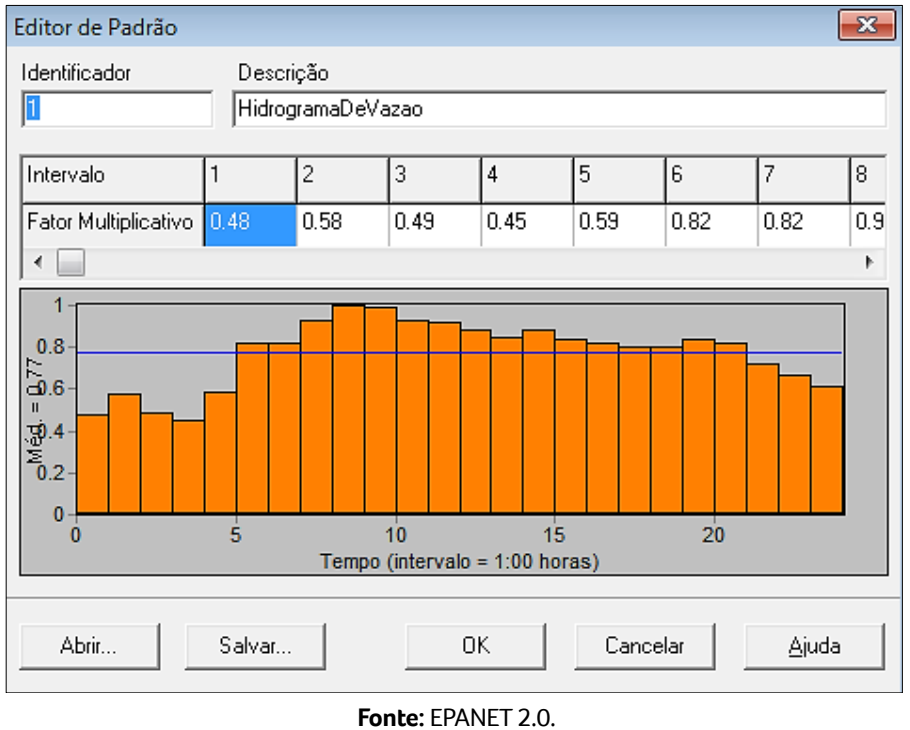

Por fim, utilizou-se um padrão de 24 horas para simular as pressões na rede ao longo do dia. Logo, foi possível analisar as variações das pressões internas da rede, observou-se que as mesmas obtidas nesta simulação se encontram no intervalo compreendido entre os 13,48 a 156,77 mca.

Com as informações obtidas diagnosticaram-se algumas zonas onde a pressão ultrapassa valor máximo recomendado pela NBR12218/2017, de $50 \mathrm{mca}$, pressões essas que comprometem a eficiência da distribuição de água, pois pressões acima de 50 mca podem causar rupturas nas tubulações e consequentemente perdas reais de água. Portanto, a setorização da rede de distribuição de água com inserção de VRPs geralmente é uma alternativa econômica para diminuir a pressão na rede e, consequentemente, reduzir o número de vazamentos nas redes de distribuição e nos ramais prediais. A setorização traria inúmeros benefícios, como: gestão das pressões no sistema, redução de gastos na manutenção da rede causados por rupturas e satisfação dos clientes.

\section{Etapa 3: Propor Três Concepções de Setorização} da Rede Distribuição de Âgua

Com o intuito de adequar as pressões internas da rede distribuição da Vila Residencial conforme recomenda a NBR 12218/2017, foram propostas três concepções de cenários setorizados da rede, por meio da inclusão ou substituição de VG por VRP no programa EPANET 2.0. Vale salientar que, como a rede de distribuição de água da Vila Residencial está implantada em uma região com topografia acidentada, é permitido pela norma que a pressão máxima estática chegue até 50 mca.

Os critérios utilizados para inserção ou substituição de VG por VRP foram: critérios hidráulicos (pressão), operacional (mais simples/menos válvulas) e econômico (menos oneroso). As concepções de setorização foram denominadas de cenários 1, 2 e 3.

É importante destacar no projeto de implantação das VRPs que a empresa faça uso de filtro a montante das válvulas redutoras de pressão, pois tal 
ação permite a proteção da mesma, e também do medidor de vazão. Caso não fosse instalado o filtro, poderia ocorrer desabastecimento devido a alguma obstrução ou desgaste prematuro na válvula, por exemplo.

\section{Simulação do Cenário 1}

Este cenário é constituído por 365 nós e 318 trechos, divididos em 15 DMCs (Fig. 7). No cenário modelado existem 45 VG e 14 VRP, totalizando 59 válvulas.

Figura 7: DMCs do cenário 1.

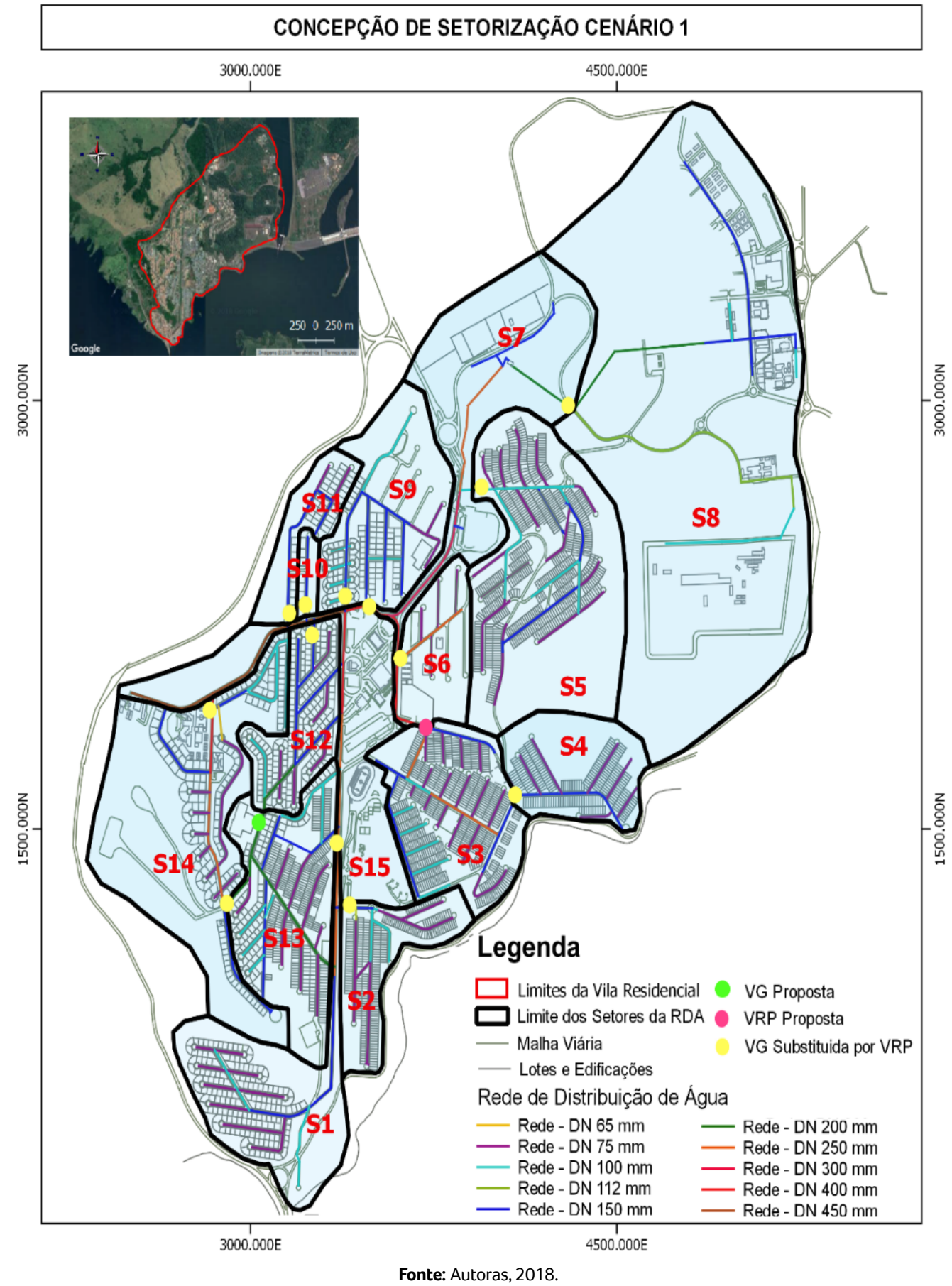


Para a primeira concepção de setorização da rede, foram manobradas algumas VG existentes e substituídas determinadas VG por VRP, além de instalar $1 \mathrm{VRP}$ e $1 \mathrm{VG}$, a fim setorizar e limitar as pressões num determinado ponto da rede.
Após a divisão da rede em DMC observou-se que as pressões variam de 10 a 105,84 mca, ao longo das 24 horas do dia, sendo que $7 \%$ dos nós estão com pressão acima de 50 mca, conforme apresentado na Fig. 8.

Figura 8: Histograma das pressões do cenário 1.

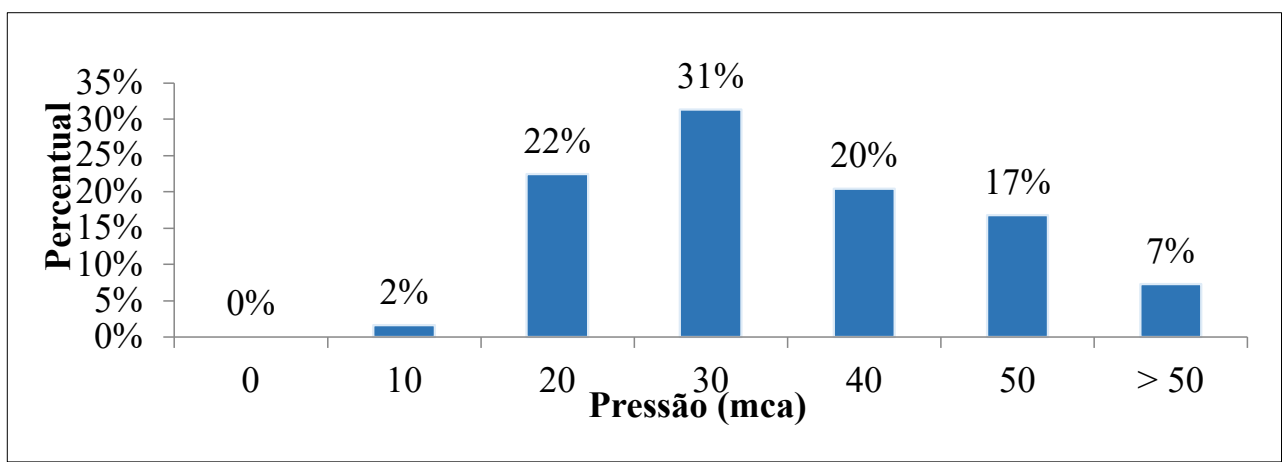

Fonte: Autoras, 2018.

Nesta concepção de setorização, alguns nós de determinados DMCs ultrapassaram as pressões máxima de 50 mca estabelecidas pela NBR 12218/2017. Os setores que não atenderam completamente às recomendações da norma foram os setores: 03, 05, 07, 09, 13 e 15. Na Tabela 3 é possível visualizar as pressões máxima e mínima de todos os setores do cenário 1 .

Tabela 3: Pressões dos setores do cenário 1.

\begin{tabular}{|c|c|c|c|c|c|c|}
\hline \multirow{2}{*}{ Setor } & \multicolumn{3}{|c|}{ Pressão Mínima } & \multicolumn{3}{|c|}{ Pressão Máxima } \\
\hline & Nó & Cota & mca & Nó & Cota & mca \\
\hline 01 & n111 & 103 & 15,54 & $\mathrm{n} 115$ & 80 & 38,91 \\
\hline 02 & n85 & 104 & 10,85 & $\mathrm{n} 206$ & 75 & 39,97 \\
\hline 03 & $\mathrm{n} 219$ & 136 & 10,93 & $\mathrm{n} 203$ & 85 & 61,89 \\
\hline 04 & n326 & 94 & 10,98 & n80 & 73,5 & 31,47 \\
\hline 05 & n18 & 124 & 11,43 & $\mathrm{n} 25$ & 74 & 61,45 \\
\hline 06 & n353 & 146 & 10,00 & $\mathrm{n} 267$ & 112 & 44,00 \\
\hline 07 & n289 & 161 & 10,00 & n344 & 65 & 105,86 \\
\hline 08 & n185 & 65 & 10,00 & $\mathrm{n} 282$ & 54 & 20,98 \\
\hline 09 & $\mathrm{n} 122$ & 187 & 10,93 & $\mathrm{n} 129$ & 143 & 54,94 \\
\hline 10 & n136 & 179 & 13,00 & n309 & 177 & 15,00 \\
\hline 11 & n133 & 182,5 & 14,50 & $\mathrm{n} 247$ & 164,5 & 32,50 \\
\hline 12 & n37 & 176 & 15,00 & $\mathrm{n} 172$ & 143 & 47,96 \\
\hline 13 & n293 & 159 & 11,90 & $\mathrm{n} 296$ & 100 & 70,98 \\
\hline 14 & n290 & 193 & 15,00 & n367 & 159 & 48,98 \\
\hline 15 & n163 & 196,6 & 13,50 & $\mathrm{n} 226$ & 120 & 89,84 \\
\hline
\end{tabular}

Fonte: Autoras, 2018. 
Ao obter os resultados, observou-se que não foi possível, em todos os nós, atender aos parâmetros exigidos pela norma, que é a pressão estática máxima de 50 mca. No entanto, com a instalação das VRPs, foi possível verificar em qual posiciona- mento as válvulas produzem o melhor desempenho em relação à redução das pressões e se realmente é necessária a instalação da VRP. A seguir, na Tabela 4, é apresentado o panorama geral dos setores do cenário 1 , após a criação dos DMCs.

Tabela 4: Panorama geral do cenário 1.

\begin{tabular}{|c|c|c|c|c|}
\hline $\begin{array}{c}\text { DMC } \\
\text { (Setor) }\end{array}$ & $\begin{array}{c}\text { Área } \\
\left(\mathbf{k m}^{\mathbf{2}}\right.\end{array}$ & $\begin{array}{c}\text { Extensão de Rede } \\
\mathbf{( k m )}\end{array}$ & \multicolumn{2}{|c|}{$\mathbf{N}^{\mathbf{0}}$ de Válvulas } \\
\hline 1 & 0,31 & 3,20 & 1 & $\mathbf{2}$ \\
\hline 2 & 0,16 & 1,91 & 1 & 2 \\
\hline 3 & 0,30 & 4,15 & 1 & 6 \\
\hline 4 & 0,20 & 1,66 & 1 & 0 \\
\hline 5 & 0,58 & 4,85 & 1 & 11 \\
\hline 6 & 0,15 & 1,26 & 1 & 1 \\
\hline 7 & 0,42 & 2,16 & 1 & 2 \\
\hline 8 & 1,41 & 3,87 & 1 & 2 \\
\hline 9 & 0,29 & 2,81 & 1 & 0 \\
\hline 10 & 0,02 & 0,30 & 1 & 0 \\
\hline 11 & 0,10 & 0,96 & 1 & 4 \\
\hline 12 & 0,16 & 2,42 & 1 & 3 \\
\hline 13 & 0,32 & 4,36 & 1 & 4 \\
\hline 14 & 0,56 & 3,70 & & \\
\hline
\end{tabular}

Como pode ser observado na Tabela 4, para a concepção de setorização do cenário 1 , a rede de distribuição da Vila Residencial foi dividida em DMC, onde determinados DMCs são controlados por uma VRP, obtendo-se assim a redução significativa na pressão a jusante da válvula. $O$ único DMC insento de VRP é o setor 15, pois, mesmo que se instale uma VRP, as pressões continuam acima de 50 mca devido à declividade topográ- fica. Vale ressaltar que as VG existentes nos respectivos DMCs são usadas exclusivamente para manutenções corretivas e preventivas na rede.

\section{Simulação do Cenário 2.}

Este cenário possui 364 nós e 317 trechos, divididos em 15 DMCs (Fig. 9). No cenário modelado existem 45 VG e 14 VRP, totalizando 59 válvulas. 
Figura 9: DMCs do cenário 2.

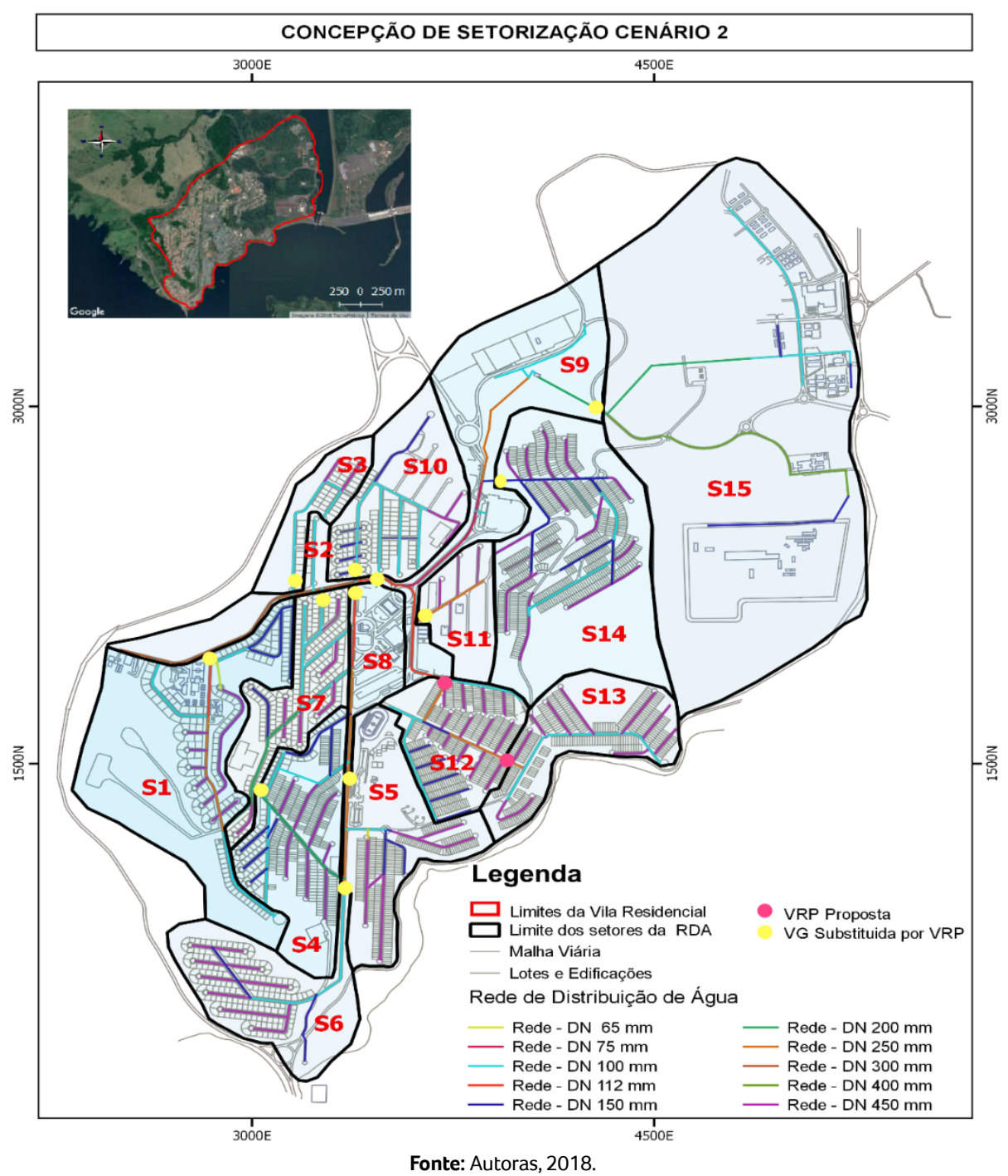

Para a segunda concepção de setorização da rede de distribuição de água, foram manobradas (closed) algumas VGs existentes e substituídas determinadas VG por VRP, além de acrescentar 2 VRP a fim de limitar as pressões num determinado ponto da rede.
Após a divisão da rede em DMC, observou-se que as pressões variam de 10 a 105,86 mca, ao longo das 24 horas do dia, sendo que $5 \%$ dos nós estão acima de 50 mca, como mostra a Fig. 10. 
Figura 10: Histograma das pressões do cenário 2.

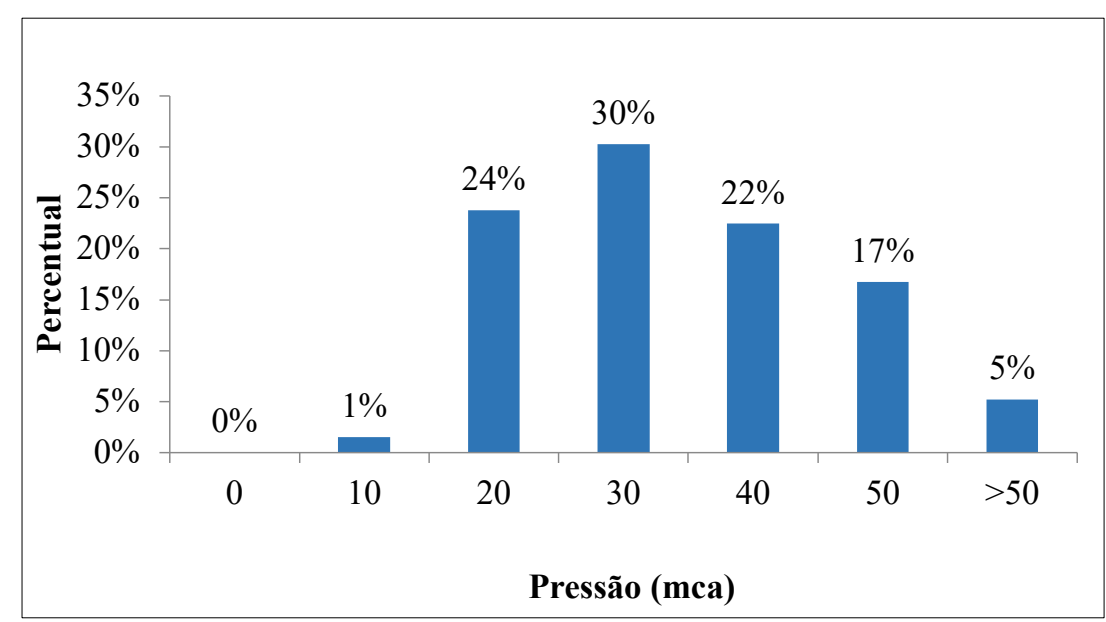

Fonte: Autoras, 2018.

Nesta concepção de setorização, alguns nós de determinados DMCs ultrapassaram também as pressões máximas de 50 mca estabelecidas pela NBR 12218/2017. Os setores que não atenderam completamente às recomendações da norma foram: 01, 04, 08, 09 e 14. Na Tabela 5 é possível observar as pressões máxima e mínima de todos os setores do cenário 1 .

Tabela 5: Pressões dos setores do cenário 2.

\begin{tabular}{|c|c|c|c|c|c|c|}
\hline \multirow{2}{*}{ Setor } & \multicolumn{3}{|c|}{ Pressão Mínima } & \multicolumn{3}{|c|}{ Pressão Máxima } \\
\hline & Nó & Cota & mca & Nó & Cota & mca \\
\hline 1 & n360 & 196,5 & 11,5 & $\mathrm{n} 224$ & 150 & 58,00 \\
\hline 2 & $\mathrm{n} 163$ & 196,5 & 13,48 & n312 & 163 & 46,94 \\
\hline 3 & n308 & 182 & 11,00 & $\mathrm{n} 247$ & 164,5 & 28,49 \\
\hline 4 & $\mathrm{n} 150$ & 159 & 10,98 & $\mathrm{n} 271$ & 100 & 66,99 \\
\hline 5 & n304 & 109 & 10,00 & $\mathrm{n} 206$ & 75 & 43,96 \\
\hline 6 & $\mathrm{n} 111$ & 103 & 10,58 & $\mathrm{n} 115$ & 80 & 33,91 \\
\hline 7 & $\mathrm{n} 230$ & 179 & 12,33 & n169 & 150 & 40,95 \\
\hline 8 & n240 & 161 & 11,00 & $\mathrm{n} 226$ & 120 & 51,98 \\
\hline 9 & n289 & 161 & 10,00 & n344 & 65 & 105,86 \\
\hline 10 & n127 & 185 & 12,92 & n14 & 148 & 49,94 \\
\hline 11 & n216 & 137,5 & 10,49 & n267 & 112 & 36,00 \\
\hline 12 & n219 & 136 & 10,94 & $\mathrm{n} 265$ & 97 & 50,00 \\
\hline 13 & n53 & 100 & 10,00 & n80 & 73,5 & 36,46 \\
\hline 14 & $\mathrm{n} 274$ & 120 & 15,50 & $\mathrm{n} 25$ & 74 & 62,45 \\
\hline 15 & n185 & 65 & 10,00 & n188 & 53 & 21,98 \\
\hline
\end{tabular}

Fonte: Autoras, 2018.

Com os resultados, constatou-se que não se conseguiu, em todos os nós, atender aos parâmetros exigidos pela norma vigente. Logo, notou-se uma melhoria considerável do desempenho da rede, e se realmente é necessário a instalação da VRP. A seguir, na Tabela 6, é apresentado o panorama geral dos setores do cenário 2 , após a criação dos DMCs. 
Tabela 6: Panorama geral do cenário 2.

\begin{tabular}{|c|c|c|c|c|}
\hline $\begin{array}{c}\text { DMC } \\
\text { (Setor) }\end{array}$ & $\begin{array}{c}\text { Área } \\
\left(\mathbf{k m}^{2} \mathbf{)}\right.\end{array}$ & $\begin{array}{c}\text { Extensão de Rede } \\
\mathbf{( k m )}\end{array}$ & \multicolumn{2}{|c|}{$\mathbf{N}^{\mathbf{0}}$ de Válvulas } \\
\hline 1 & 0,56 & 3,70 & 1 & $\mathbf{V R}$ \\
\hline 2 & 0,11 & 1,40 & 0 & 2 \\
\hline 3 & 0,11 & 0,96 & 1 & 0 \\
\hline 4 & 0,3 & 3,79 & 1 & 2 \\
\hline 5 & 0,29 & 2,42 & 1 & 3 \\
\hline 6 & 0,28 & 2,70 & 1 & 1 \\
\hline 7 & 0,21 & 3,00 & 1 & 4 \\
\hline 8 & 0,11 & 0,81 & 1 & 0 \\
\hline 9 & 0,44 & 2,50 & 1 & 7 \\
\hline 10 & 0,27 & 2,81 & 1 & 2 \\
\hline 11 & 0,13 & 0,91 & 1 & 0 \\
\hline 12 & 0,21 & 3,42 & 1 & 3 \\
\hline 13 & 0,24 & 2,40 & 1 & 4 \\
\hline 14 & 0,61 & 4,85 & 1 & 11 \\
\hline 15 & 1,42 & 3,87 & 1 & 2 \\
\hline TOTAL & 5,29 & 39,52 & 14 & 45 \\
\hline
\end{tabular}

Fonte: Autoras, 2018.

Como pode ser observado na Tabela 6, para a proposta de setorização do cenário 2 , a rede de distribuição da Vila Residencial foi dividida em DMC, onde cada DMC é controlado por uma VRP, obtendo-se, assim, a redução significativa na pressão a jusante da válvula.

\section{Simulação do Cenário 3.}

Este cenário é constituído por 369 nós e 318 trechos, divididos em 21 DMCs (Fig. 11). No cenário modelado existem 42 VG e 20 VRP, totalizando 62 válvulas.
Para a terceira concepção de setorização da rede, também foram manobradas (closed) algumas VGs existentes e substituídas determinadas VG por VRP, além de acrescentar 4 VRP e 1 VG, a fim de limitar as pressões num determinado ponto da rede.

Após a divisão da rede em DMC observou-se que as pressões variam de 10 a 105,84 mca, ao longo das 24 horas do dia, com apenas $1 \%$ dos nós acima de $50 \mathrm{mca}$, conforme apresentado na Fig. 12. 
Figura 11: DMCs do cenário 3.

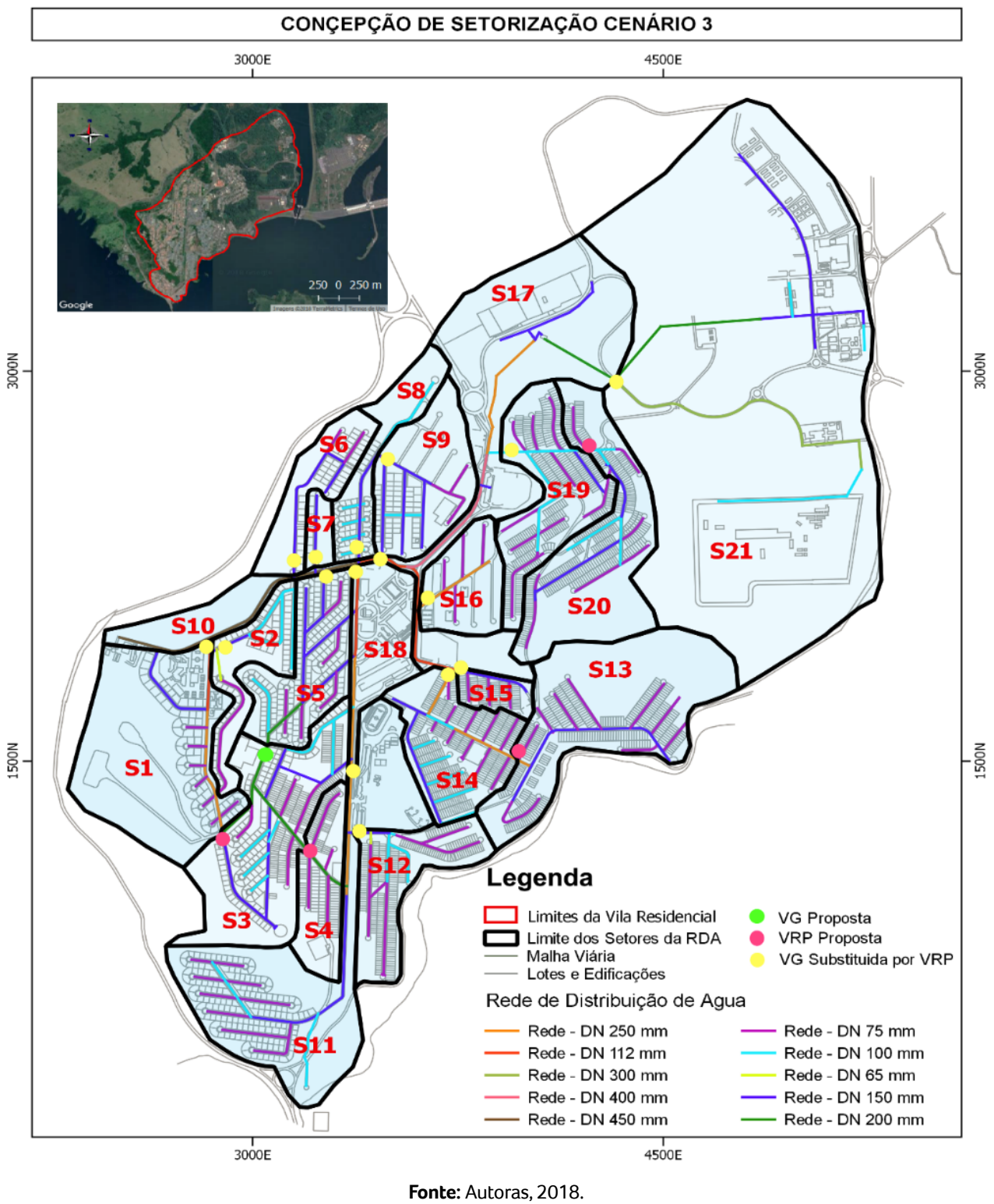

Figura 12: Histograma das pressões do cenário 3.

\begin{tabular}{|c|c|c|c|c|c|c|c|}
\hline \multirow[t]{3}{*}{ 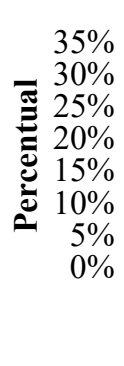 } & $0 \%$ & $4 \%$ & $33 \%$ & $32 \%$ & $20 \%$ & $10 \%$ & $1 \%$ \\
\hline & 0 & 10 & 20 & 30 & 40 & 50 & $>50$ \\
\hline & \multicolumn{7}{|c|}{ Pressão (mca) } \\
\hline
\end{tabular}

Fonte: Autoras, 2018. 
Este $1 \%$ refere-se a apenas um nó, que pertence ao setor 17. Admite-se que a base do problema neste nó esteja unicamente relacionada à topografia, pois está localizado em uma cota muito elevada em relação ao nó a montante. Na Tabela 7, é possível observar as pressões máxima e mínima de todos os setores do cenário 3 .

Tabela 7: Pressões dos setores do cenário 3.

\begin{tabular}{|c|c|c|c|c|c|c|}
\hline \multirow{2}{*}{ Setor } & \multicolumn{3}{|c|}{ Pressão Mínima } & \multicolumn{3}{|c|}{ Pressão Máxima } \\
\hline & Nó & Cota & mca & Nó & Cota & mca \\
\hline 1 & n360 & 196,5 & 11,5 & n364 & 159 & 48,98 \\
\hline 2 & n300 & 191 & 10 & $\mathrm{n} 179$ & 167 & 34 \\
\hline 3 & n363 & 159 & 10 & n366 & 121 & 47,99 \\
\hline 4 & n139 & 121 & 10 & $\mathrm{n} 296$ & 100 & 31 \\
\hline 5 & $\mathrm{n} 230$ & 179 & 11,97 & n170 & 148,5 & 42,45 \\
\hline 6 & n133 & 182,5 & 10,5 & $\mathrm{n} 132$ & 166 & 27 \\
\hline 7 & n134 & 179,5 & 12,5 & n309 & 177 & 15 \\
\hline 8 & $\mathrm{n} 122$ & 187 & 10,98 & $\mathrm{n} 251$ & 156 & 41,96 \\
\hline 9 & $\mathrm{n} 254$ & 168 & 10,99 & n129 & 143 & 35,98 \\
\hline 10 & $\mathrm{n} 163$ & 196,5 & 13,5 & n312 & 163 & 46,94 \\
\hline 11 & n304 & 109 & 10 & $\mathrm{n} 115$ & 80 & 38,9 \\
\hline 12 & n84 & 104 & 10,95 & n206 & 75 & 39,96 \\
\hline 13 & n53 & 100 & 10 & n80 & 73,5 & 36,46 \\
\hline 14 & $\mathrm{n} 219$ & 136 & 10,98 & n371 & 100 & 46,8 \\
\hline 15 & n318 & 120 & 10 & n265 & 97 & 33 \\
\hline 16 & n315 & 130 & 18 & n267 & 112 & 36 \\
\hline 17 & $\mathrm{n} 289$ & 161 & 10 & n344 & 165 & 105,84 \\
\hline 18 & n311 & 160 & 11 & $\mathrm{n} 226$ & 120 & 50 \\
\hline 19 & n338 & 120 & 17 & n369 & 91 & 45,44 \\
\hline 20 & n191 & 91 & 12 & n22 & 99 & 37,47 \\
\hline 21 & n185 & 65 & 10 & n282 & 54 & 20,98 \\
\hline
\end{tabular}

Como se pode facilmente averiguar, neste cenário os nós com pressão acima do limite legal (50 mca) quase que foram eliminados, e conseguiu-se baixar as pressões na generalidade do sistema sem que com isso se comprometesse a pressão dinâmica mínima (10 mca).

A seguir, na Tabela 8, é apresentado o panorama geral dos setores do cenário 3, após a criação dos DMCs. 
Tabela 8: Panorama geral do cenário 3

\begin{tabular}{|c|c|c|c|c|}
\hline \multirow{2}{*}{$\begin{array}{c}\text { DMC } \\
\text { (Setor) }\end{array}$} & \multirow{2}{*}{$\begin{array}{c}\text { Área } \\
\left(\mathbf{k m}^{2} \mathbf{)}\right.\end{array}$} & $\begin{array}{c}\text { Extensão de Rede } \\
\mathbf{( k m )}\end{array}$ & \multicolumn{2}{|c|}{$\mathbf{N}^{\mathbf{0}}$ de Válvulas } \\
\hline 1 & 0,36 & 1,62 & 1 & $\mathbf{V}$ \\
\hline 2 & 0,11 & 1,64 & 1 & 0 \\
\hline 3 & 0,29 & 3,81 & 1 & 5 \\
\hline 4 & 0,11 & 0,95 & 1 & 1 \\
\hline 5 & 0,16 & 2,46 & 1 & 3 \\
\hline 6 & 0,11 & 0,96 & 1 & 0 \\
\hline 7 & 0,03 & 0,30 & 1 & 0 \\
\hline 8 & 0,1 & 1,10 & 1 & 0 \\
\hline 9 & 0,18 & 1,71 & 1 & 1 \\
\hline 10 & 0,09 & 1,10 & 1 & 0 \\
\hline 11 & 0,41 & 3,17 & 1 & 2 \\
\hline 12 & 0,15 & 1,91 & 1 & 2 \\
\hline 13 & 0,35 & 2,40 & 1 & 3 \\
\hline 14 & 0,18 & 2,80 & 1 & 2 \\
\hline 15 & 0,04 & 0,61 & 1 & 0 \\
\hline 16 & 0,1 & 0,91 & 1 & 0 \\
\hline 17 & 0,47 & 2,50 & 1 & 7 \\
\hline 18 & 0,12 & 0,85 & 1 & 0 \\
\hline 19 & 0,19 & 2,60 & 1 & 6 \\
\hline 20 & 0,23 & 2,25 & 1 & 5 \\
\hline 21 & 1,51 & 3,87 & 1 & 2 \\
\hline TOTAL & 5,29 & 39,52 & 21 & 41 \\
\hline & & & 1 & \\
\hline
\end{tabular}

Fonte: Autoras, 2018.

Para a concepção de setorização do cenário 3, a rede de distribuição da Vila Residencial foi dividida em DMC, onde cada DMC é controlado por uma VRP, obtendo-se, assim, a redução significativa na pressão a jusante da válvula.

\section{Etapa 4: Comparação e Escolha do Melhor} Cenário Setorizado da Rede de Distribuição de Água

A fim de comparar e escolher a melhor concepção de setorização da rede, foram gerados no EPANET 2.0 gráficos de isolinhas de cada cenário. Utilizou-se também o Microsoft Excel para a análise estatística do comportamento das pressões ao longo das 24 horas do dia, gerando, assim, um histograma de pressão. Além disso, comparou-se o custo de setorização de cada cenário com base no banco de dados da SEINFRA 024, fornecido pelo software OrçaFascio.

\section{Atividade 4.1: Análise das Pressões na Simulação Hidráulica}

Para a análise das pressões foram gerados os gráficos de isolinhas no Software EPANET 2.0, a fim de obter uma visualização das zonas onde as pressões estão acima de 50 mca. A Fig. 13 apresenta os gráficos de isolinhas dos cenários. 
Figura 13: Gráficos de isolinhas.

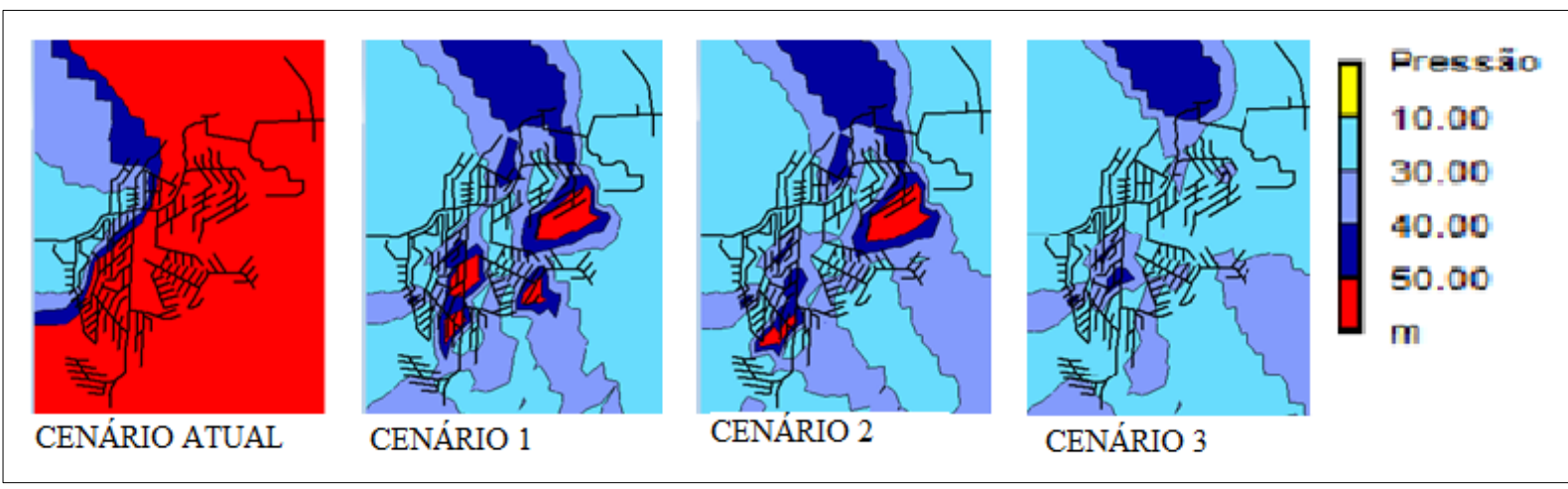

Fonte: EPANET 2.0.

No panorama geral, ao se comparar os gráficos de isolinhas do EPANET 2.0, que representa o nível atual de pressões existentes na rede de distribuição, nota-se uma mudança perceptível na redução relativa às pressões existentes do cenário atual da rede após a introdução das VRP. Os gráficos de isolinhas dos cenários 1 e 2 apresentam valores de pressão acima dos $50 \mathrm{mca}$ em alguns nós da rede; levando-se em consideração os valores máximos, o cenário 3 apresenta-se como sendo a melhor opção.

\section{Atividade 4.2: Análise Estatística das Pressões}

Para melhor visualização da variação das pressões em todos os nós da rede de distribuição da Vila Residencial em cada um dos cenários, utilizou-se um histograma horário referente à simulação das 24 horas do dia, cujo objetivo é comparar o comportamento das pressões dos respectivos cenários, conforme mostra a Fig. 14.

Figura 14: Gráfico comparativo dos histogramas das pressões de cada cenário.

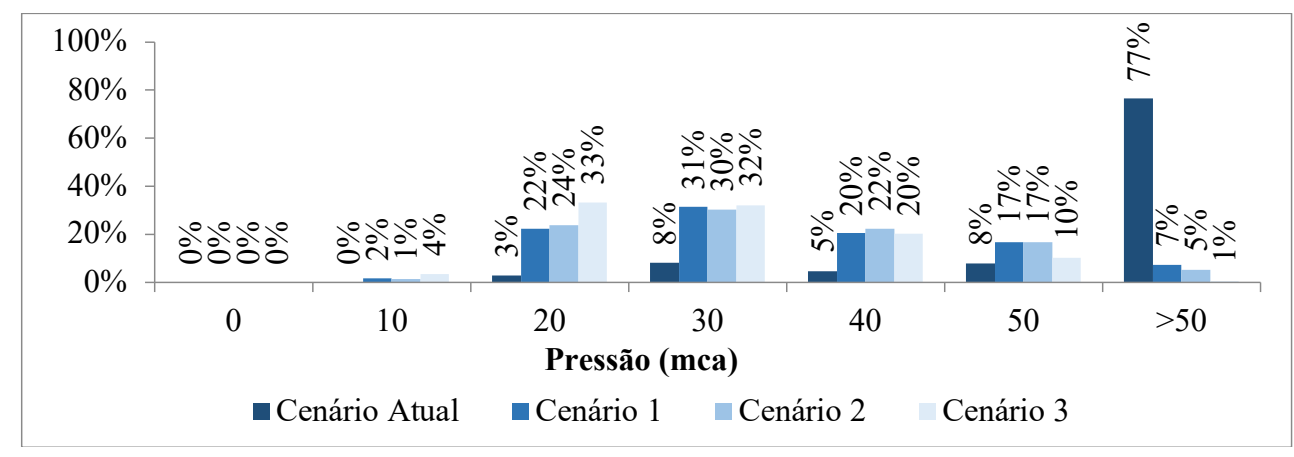

Fonte: Autoras, 2018

Observa-se que nenhum deles apresenta pressões dinâmicas abaixo de 10 mca. Em relação à pressão estática máxima de $50 \mathrm{mca}$, o cenário 3 apresentou o melhor resultado, atendendo às recomendações NBR 12218/2017 em 99\% das ocorrências. 0 cenário 1 e o cenário 2 atenderam à norma respectivamente $93 \%$ e $98 \%$ das ocorrências. 
Atividade 4.3: Análise do Custo para a Setorização de cada Cenário.

Ainda que os cenários estejam hidraulicamente otimizados, para a escolha do melhor cenário deve ser levado em conta o aspecto econômico, ou seja, a quantidade de VRP necessárias para a setorização de cada cenário, conforme mostra a Tabela 9.

Tabela 9: Total de VRPs utilizadas em cada cenário.

\begin{tabular}{|c|c|c|c|}
\hline $\begin{array}{c}\text { Diâmetro } \\
\text { (mm) }\end{array}$ & $\begin{array}{c}\text { Cenário 1 } \\
\text { (VRP) }\end{array}$ & $\begin{array}{c}\text { Cenário 2 } \\
\text { (VRP) }\end{array}$ & $\begin{array}{c}\text { Cenário 3 } \\
\text { (VRP) }\end{array}$ \\
\hline 100 & 1 & 1 & 2 \\
\hline 150 & 6 & 4 & 8 \\
\hline 200 & 2 & 2 & 2 \\
\hline 250 & 1 & 3 & 5 \\
\hline 400 & 4 & 4 & 3 \\
\hline Total & 14 & 14 & 20 \\
\hline
\end{tabular}

Para determinação do orçamento com a aquisição das válvulas, utilizou-se o software OrçaFascio para o levantamento do preço unitário das
VRPs, de acordo com os diâmetros desejados de cada cenário. 0 orçamento está bem representado no gráfico da Fig. 15.

Figura 15: Custo total de cada cenário para aquisição das VRPs.

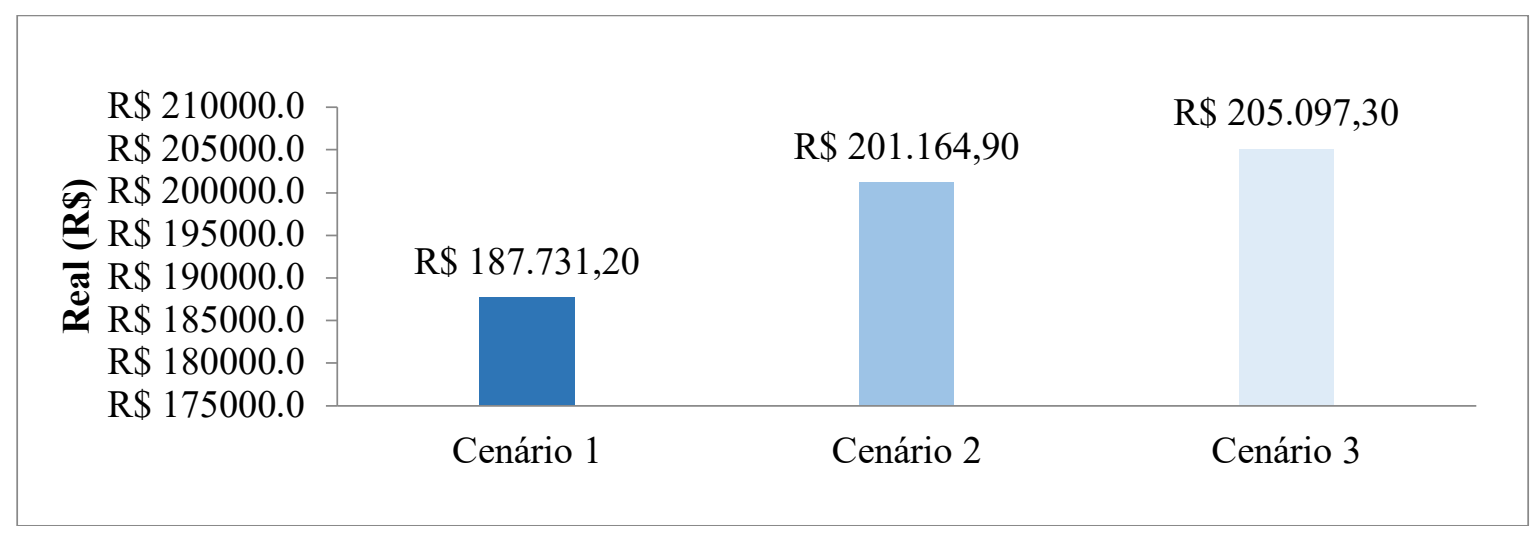

Fonte: Autoras, 2018.

O custo total com a aquisição de 14 VRPs propostas para a setorização da rede no cenário 1 é de $\mathrm{R} \$ 187.731,20$. No cenário 2 , tem-se um custo de $\mathrm{R} \$ 201.164,90$ para a compra de 14 VRPs, havendo um aumento de $\mathrm{R} \$ 13.433,70$ quando comparado ao cenário 1. Já no cenário 3 , o custo com a compra das 20 VRPs foi de $\mathrm{R} \$ 205.097,30$, um aumento de $R \$ 17.366,10$ quando comparado ao cenário 1 .

\section{CONSIDERAÇÕES FINAIS}

Face às características das concepções dos cenários, visando beneficiar o planejamento e o controle da operação e o controle das pressões, constatou-se que, dos três cenários propostos, o cenário 3 é o que pode ser caracterizado como a melhor proposta de setorização, pois apresentou o melhor desempenho hidráulico, apesar de não apresentar o menor custo de implantação. 
Contudo, ambas as concepções de setorização apresentadas possuem suas vantagens e desvantagens quando analisados o custo-benefícioficando, assim, a cargo da entidade gestora a escolha da setorização da rede.

Por fim, a melhor setorização da rede é aquela que torna mais fácil qualquer atividade de manutenção, por atingir um número menor de unidades de consumo. Quanto menor o setor de manobras, menores serão as chances da ocorrência de interrupções no abastecimento causadas por manutenção de rupturas.

\section{CONTRIBUIÇÃO DOS AUTORES}

Todos os autores contribuíram de forma igualitária.

\section{REFERÊNCIAS}

ASSOCIAÇÃO BRASILEIRA DE NORMAS TÉCNICAS - ABNT. NBR 12218:2017 - Projeto de rede de distribuição de água para abastecimento público - Procedimento. Rio de Janeiro, 2017.

BEZERRA, S. T. M. et al. Controle Automático de Pressão em Sistemas de Distribuição de Água. Capítulo 1. In: Heber Pimentel Gomes (Org). Sistema de Saneamento: Eficiência Energética. João Pessoa: Editora Universitária/UFPB, 2010. Disponível em: <http:// www.lenhs.ct.ufpb.br/wp-content/uploads/arquivos/LiVGo_Eficiencia_Energetica.pdf> Acesso em: 12 abr. 2018.

DIUANA, F. A.; OGAWA, S. C. C. P. Análise Comparativa dos Modelos Hidráulicos Epanet, Water CAD e Sistema UFC para Sistemas de Abastecimento de Água. Projeto de Graduação (Curso de Engenharia Ambiental) UFRJ/ Escola Politécnica, 2015. Rio de
Janeiro, 2015. Disponível em: <http://monografias.poli.ufrj.br/ monografias/monopoli10013745.pdf>. Acesso em: 20 abr. 2018.

GOMES, R. J. Modelação matemática como ferramenta de gestão e exploração de sistemas de distribuição de água. Tese (Doutorado em Engenharia Civil na especialidade de Hidráulica, Recursos Hídricos e Ambientes) - Faculdade de Ciências e Tecnologia da Universidade de Coimbra, 2011. Disponível em: <https:// estudogeral.sib.uc.pt/handle/10316/17988>. Acesso em: 05 jul. 2018.

MOTTA, R. Importância da setorização adequada para combate às perdas reais de água de abastecimento público. Dissertação (Mestrado em Engenharia Hidráulica e Sanitária) - Escola Politécnica da Universidade de São Paulo. São Paulo, 2010. Disponível em: <http://www.teses.usp.br/teses/disponiveis/3/3147/tde18082010-171334/pt-br.php>. Acesso em: 27 jun. 2018.

OLIVEIRA, F.M. R. Redução de perdas reais em sistemas de abastecimento de água: otimização das pressões numa grande rede de distribuição de água - aplicação ao caso do porto. Dissertação (Mestrado em Engenharia Civil) - Faculdade de Engenharia da Universidade do Porto. Portugal, 2013. Disponível em: <https:// webcache.googleusercontent.com/search?q=cache:eoZDxEzs22EJ:https://sigarra.up.pt/feup/pt/pub_geral.show_file\%3Fpi_ gdoc_id\%3D360844+\&cd=7\&hl=pt-BR\&ct=clnk\&gl=br>. Acesso em: 31 mar. 2018.

ORÇAFASCIO. Software para Engenharia. STABILE-SBC SISTEMAS E CONSULTORIA DE CUSTOS LTDA. Disponível em: <https:// www.orcafascio.com/>. Acesso em: 25 de jun. 2018.

ROSSMAN, L. A. et al. EPANET 2.0: Manual do Usuário. U. S. Environmental Protection Agency, Cincinnati, Ohio, 2000. Disponível em: <http://www.lenhs.ct.ufpb.br/html/downloads/epanet/manual_do_epanet_brasil.pdf>. Acesso em: 17 jan. 2018.

SEINFRA. Secretaria da Infraestrutura do Estado do Ceará. Tabela de Custo Unificada- Versão 024. Fortaleza, CE, 2017. Disponível em; <http://www.seinfra.ce.gov.br/index.php/downloads/category/24-tabela-de-custos-verso-024>. Acesso em: 25 jun. 2018. 